\title{
Transformation of Social-Personal Mindsets Using MASTER-KIT Technique as a Scientific and Practical Problem
}

\author{
Darya R. Kuramshina ${ }^{1}$, Daniya Z. Akhmetova ${ }^{1}$ \& Ilona G.Morozova ${ }^{1}$ \\ ${ }^{1}$ Kazan Innovative University named after V. G. Timiryasov, Kazan, Russian Federation \\ Correspondence: Daniya Z. Akhmetova, Kazan Innovative University named after V.G. Timiryasov, Kazan city, \\ zip code 420111, 42 Moscovskaya str., Russian Federation. E-mail: imorozova323@gmail.com
}

Received: March 6, 2019

Accepted: April 19, 2019

Online Published: April 22, 2019

doi:10.5539/ijps.v11n2p62

URL: https://doi.org/10.5539/ijps.v11n2p62

\begin{abstract}
The article is devoted to the methodological basis of study the problem of the personal and social homeostasis as the manifestation of satisfaction with life, i.e., happiness. The West European and American theories of personality are characterized, they serve as the methodological basis for constructing and justifying the authors' technique for achieving individual and group goals. The authors' technique "Master KIT" was tested on 101 participants and showed a positive dynamics in improving the well-being, mood and activity, psychological state. The issues of an objective assessment of changes that arise on the physical and psychological state of clients, their social well-being while using the technigue are relevant. The obtained data will help with the subsequent interpretation of the possibilities of applying the methodology, forming recommendations and improving the procedure of using this technique. Scientific research will contribute to solving practical problems aimed at optimizing a software product, expanding the available product functions, and also has theoretical significance in studying the mechanisms of influence of a technique on a person.
\end{abstract}

Keywords: homeostasis, transformation, development, social-personal mindsets, Master-KIT technique

\section{Introduction}

D. N. Uznadze (1949) defines "a mindset" as a state comprising both physiological and psychological component, implying the readiness of an individual to certain activity in his work "Experimental basis of the psychology of mindsets". Occurrence of this activity depends on the need existing in the body, and on the objective situation in which the need will be satisfied. But in relation to the situation, the mindset is primary, integral, undifferentiated state. There are such states of the mindset as fixity, durability, dynamics, static nature, plasticity, roughness, irradiation, generalization, constancy, variability, stability, labiality, intermodality. Two elementary conditions are enough for appearance of a mindset - actual needs of a subject and a situation of their satisfaction (Uznadze, 1949.)

In terms of psychology and psychotherapy, transformation is a certain change of personality or changes of certain mindsets, attitudes, transformation of structures, forms and means, change of target orientation of activity. Transformation is the breakage of links between the mindset and the desired. The process of transformation enables to broaden the boundaries of subjective reality of a person, which leads to determining the possibilities to reach the desired, eliminating the negative mindset, and forming the new.

The research is aimed at revealing the achieving well-being, internal harmony and homeostasis by people using the Master-Kit technique.

\subsection{The Study of Human's Personality and Social Homeostasis}

The theoretical-methodological base of the present study is presented in the researches of Russian and foreign researchers, such as A. Adler (1986), W. James (1991), J. Dispenza (2008), J. Kehoe (2006), A. Maslow (1995), Z. Freud (1989), E. Fromm (2006), V. Frankl (1986), C. Jung (1994), A. N. Leontyev (1983), S. L. Rubinstein (1957), D. N. Uznadze (1949), other scientists. We apply interdisciplinary approach, which is reflected in the analysis of the human mentality features through the medical, physiological and philosophic viewpoints. The research is based on several methodological approaches.

First, it is the personality theory by William James (1991), who believed that "a personality appears as the interaction of instinctive and familiar sides of consciousness, as well as personal volitional aspects". James's 
doctrine of the physical, social and spiritual personality is valuable for understanding the social aspects of empirical research. The scholar highlights the importance of an adequate self-assessment of a personality as the focus of personal growth.

The key discovery, made by Dr. Joe Dispenza, is that a brain does not distinguish the physical experiences from the spiritual ones. According to this researcher, the brain cells cannot distinguish between the real, i.e. material, from the imaginary, i.e. the thoughts. According to Dr. Dispenza's theory, when we experience something, we activate a large number of neurons in our brain, which influence our physical state. "It is the phenomenal power of consciousness, due to the ability to concentrate, that creates synaptic links - links between neurons" (James, 1991). Our experiences, thoughts, feelings, frequently repeating, create stable neuron links, in other words, neuron networks. Each network is certain reminiscence, based on which, our body will react on similar situations and objects.

According to Dr. Dispenza (2008), everything we experienced in the past is "recorded" in neuro-networks of the brain which form both our perception and sensation of the world in general, and it specific objects in particular; thus, it can be said that our reactions just seem to be spontaneous. Actually, most of them are programmed by stable neuron links. Each stimulus (object) facilitates activation of a particular neuron network, which causes a set of particular chemical reactions in the body. In $99 \%$ of cases we perceive the reality not as it is but interpret it basing on the ready patterns from the past.

Joe Dispenza bases his conceptions on the idea that a person is a creator of their own being. These ideas are similar to those expressed in the works by John Kehoe (2001). Working with the subconscious requires exclusion of fear and guilt to free the brain for creation, not destruction. It should be taken into account that destructive programs are built into subconsciousness by the society, mass media, education, everyday life and everything which a person does consciously and subconsciously.

Managing the subconscious provides $90 \%$ of successful and happy life. To achieve the desired, one must restructure, redirect the resources of the subconsciousness: to insert new adaptive mindsets, programs, facilitating the problem solving; to give the new positive commands to oneself. The first steps in discovering the secrets of the subconsciousness are deep analysis of one's internal condition, understanding of the intentions and actual problems, switching off the uncontrollable subconscious "autopilot".

We also analyzed the mechanisms of the subconscious investigated by Zigmund Freud. Freud bases his theoretical research on the fact that "there are no breaks and inconsistencies in spiritual life. Each idea, reminiscence, feeling or action has its own reason; they are caused by conscious or subconscious intentions" (Freud, 1989).

Interpretation of the interconnection between the "consciousness", "subconsciousness" and "the unconscious" are in the basis of "Master KIT" experimental technique. Z. Freud's theory of the structure of the personality and mental "apparatuses" - "ego", and "superego", - and sublimation mechanisms became the scientific platform of arranging the experiment on transforming the mindsets for achieving the individual and personal goals.

The main point of analytical psychology by C. Jung (1994), which views the categories of "the collective unconscious" is the following: he proves that "the collective unconscious constellates in large social groups and that when the collective unconscious is activated, a person stops being oneself" (Jung, 1994). This idea is also valuable for determining the social significance of the research.

A. Adler's personality theory and especially his scientific conceptions of the "inferiority complex" and "compensation" gives us the folloing methodology. A strong feeling of inferiority ("inferiority complex") can obstruct the positive growth. The following statement is very important for us: "The desire for perfection is innate, in the sense that it is a part of life, a desire or need, without which life would be unthinkable" (Adler, 2010) . A. Adler's theory of life goals is based on the fact that "the life goal of each individual is formed under the influence of their personal experience, values, relationships, characteristics of the personality. A life goal is not something that is clear and consciously chosen. They provide the direction and tasks for our activity, they give the opportunity to interpret various aspects of thinking and behavior to an external observer" (Adler, 1986).

E. Fromm's (1997) research of a personality in modern culture also plays an important role in our study. E. Fromm asserts that "a person is a social being, experiencing deep need to share with others, to help them, to feel oneself as a member of the group" (Fromm, 1997). It should be taken into account that, according to E. Fromm, a person is driven by egoistic interests and not the feeling of solidarity and love for one's neighbour; however, in the social sphere "the state serves as the embodiment of our social existence", and a person must execute their social duties (Fromm, 2006). 
Our research is based also on the principles of Gestalt psychology. Gestalt psychology (from German Gestalt personality, image, form) is a psychological doctrine of the beginning of the $20^{\text {th }}$ century. It was founded by Max Wertheimer, Wolfgang Köhler and Kurt Koffka in 1912.

To define the role of insight, we rely on the opinion of Köhler (1998), who believed that the initial comprehension of the general picture is after some time substituted by a more detailed differentiation, which serves as the basis for a new, more adequate in the particular situation, gestalt. Thus, W. Köhler defined insight as problem solution based on comprehending the logical links between stimuli or events (Köhler, 1998).

Cognitive psychology researches the processes of cognition, taking place in the human mind. Special attention is paid to such practical sphere as cognitive-behavioral psychotherapy, which includes a "construct" - classifier of a person's perception of oneself and other people. A person with sound mind transforms it or rejects it in search of new constructs.

The "block" representation of the information processing models, proposed by cognitive psychologists, served as the basis for elaborating software for computer modeling of a personality mindset. This is a new approach to constructing a psychotherapeutic process through transformation of the social-personal mindsets of the experiment participants.

The research is based on personality theory by A. Maslow (1970). The main concepts of self-actualization, his hierarchy of needs, meta-motivation, and the problem of centering are the basis of auto-training activity. A. Maslow asserts that "self-actualization is not the absence of problems, but the movement from transient and unreal problems to the real ones" (Maslow, 1970). Building the hierarchy of fundamental human needs dynamics (physiological needs, need for safety, need for love and belonging (social), need for respect (status), need for self-actualization), Maslow states that "a person can live by bread alone - if a person does not have enough bread. But what happens with the people's wishes, if there is enough bread, when their stomachs are always full? Immediately appear other, higher needs, and begin to dominate in the body. When these are satisfied, new, still higher needs come forward, and so on" (Maslow, 1995).

Homeostasis can be defined as "any self-regulating process with the help of which the biological systems strive for maintaining their internal stability, adapting to the conditions optimal for survival. If homeostasis is successful, life goes on; otherwise, a disaster or death occurs. The achieved stability is actually a dynamic equilibrium, in which perpetual changes take place, but relatively homogeneous conditions prevail" (Anokhin, 1998).

Social homeostasis implies manifestation of a harmonious development of the society. It also explains the stable interaction and the character of activity of a personality in the system of social relations.

Social homeostasis is only possible if, first, the internal harmony of a person is provided, which promotes harmonization of their interaction with the external environment (society); second, if a person is not left alone face to face with the complexities of life, not able to use the methods and skills to overcome their frustration. The optimal interaction of a personality with the society and various groups (professional, informal, interest groups, etc.) serves as a guarantee of providing both personal (individual) and group homeostasis. Social homeostasis is a universal mechanism maintaining the stable development of a society, its dynamics without social shocks.

One of the conditions for ensuring the social homeostasis is the inner satisfaction of a personality with their life, the state of happiness. "Happiness" as a psychological category has been studied for a long time, but there is still no clear definition of this phenomenon.

There are different points of view on the essence of "happiness". In the social aspect, most people perceive "happiness" as material well-being, high social status, availability of the necessary amount of money and social goods. There are several scenarios which make people happy: the first is the pleasure from material well-being, hedonism; the second is the pleasure from implementing one's projects; the third is the sense of one's devotion and talent, its recognition by the surrounding people.

A person who wishes to be happy must define and recognize what they lack in life. The process of achieving happiness (which is always individual) is conjugated with the feeling of frustration and understanding of the necessity to overcome it. Not every individual has enough knowledge and ability to reach such internal state. In most cases it is due to the lack of means and mechanisms of achieving homeostasis, one of the indicators of the state of happiness and satisfaction with life.

There is an opinion that happiness is a state of euphoria. Euphoria (Greek - state of pleasure) is a sudden experience of enthusiasm, good spirits, a feeling of optimism, absolute well-being. 
Although these emotions are positive, psychologists often regard euphoria as a disease state, occurring most often as a result of brain lesions (hypoxia, traumas). If euphoria is caused by using substances or alcohol, it is followed by depression or frustration. If euphoria is experienced by a mentally healthy person, and it is caused by satisfaction from settling some internal problems, then one may assert that it is not a consequence of some unhealthy body reactions. Studying the works by the founders of existential psychotherapy Ludwig Binswanger (1954), Viktor Frankl (2006) we assume that euphoria is linked to the "existence" ("genuine life"), when a person copes with the arising barriers and difficulties. The state of euphoria, which appears after liberation from barriers and the "disturbing files" of the subconscious, causes a feeling of internal freedom as an indispensible condition of achieving happiness (Frankl, 2006). Russia ranks the $40^{\text {th }}$ by the level of happiness among the 58 researched countries. There are less happy people in Russia than in the world in general (39\% against 53\%). The share of respondents who gave a neutral answer "neither happy nor unhappy" is $42 \%$, which testifies to the features of the national culture and mentality of the Russians. The researches assert that many respondents denote satisfaction with life as happiness. At the same time, there are a lot more people who wish to become happy, to feel the fullness of life, but they do not know the "way to happiness", do not know how to reach homeostasis as the basis of happiness.

We also have analysed the works of Antinen (2013), Arean (2016), Christopher ( 2009), Cohn (2009), Creswell (2017), Cujpers (2012) who studied the issues of happiness, depression, emotionl state and other researchers.

Another important object of our study - is a mind-set. Mind-set is the connection between the desired and the intended consequence of the fulfillment of the desire. They can be conscious or unconscious. There are two types of attitudes: positive and negative. The positive mind-sets express favorable pleasant result of the desire. Positive mind-sets contribute to the achievement of the goal, to achieve the desired, to meet the needs. Negative mind-sets express unfavorable, result of the fulfillment of his desire. In the process of using the technique "Master KIT" unconscious negative mind-sets are revealed and their subsequent transformation is happened. According to the author of the technique, transformation of a mind-set is a break in the connection between the mind-set and the desired. The process of transformation allows to expand the boundaries of the subjective reality of the person, which leads to the determination of the possibility of achieving the desired, leveling the negative mind-set,the formation of positive attitudes. The result of transformation can be responsibility and consciousness.

The present study is based on the cognitive-behavioral approach. Great importance in the framework of the cognitive-behavioral approach is given to the relationship between the stimulus, its mental processing and the final reaction in the form of emotional and behavioral response. Within the framework of the cognitive-behavioral approach, the most common formula is: A (event) - B (attitudeslbeliefs) - C (consequences/reaction). According to this approach, a certain event that took place in reality is processed in a special way by cognitive processes.

We also studied the researchers conducted on the same subjects using other techniques. The scientists from University College (London) have studied the influence consciousness on stress on the workplace in two big multinational corporations, using Headspace application. The research showed the increase of wealfare, reducing anxiety and depression syndrome. Another study was devoted to the influence of on-line trainings on behavioral patterns of wandering mind (Bennike, Wieghorst \& Kirk, 2017).

There is also the study of using computer-assisted cognitive therapy and its influence on intensity of depression syndrome (Wright et al, 2005). The authors of study got the result that computer-assisted cognitive therapy and standart cognitive therapy had the same effectiveness. The computer assisted therapy can reduce costs and improve the access to cognitive therapy which aimed to treat the depression.

There is also an interesting study devoted to the using of training OIVA (Ahtinen et al, 2013) . During this study the using of this mobile application, its effectiveness for teaching the skills of mental wel-fare skills among people of working age was studied. The results of study showed the increase of life satisfaction level and reduce the level of stress.

\subsection{Master-KIT Technigue and Its Theoretical Basis}

The "Master KIT" is an automated psychological self-regulation simulator aimed at acquiring users of the product with the skills to solve their actual goals and objectives. Despite the extensive customer base that is actively using the product (more than 20,000 people), the issues of an objective assessment of the extent of changes that occur when using the method, the physical and psychological state of clients, their social well-being remain relevant. The technique is based on such methodological principles as dynamic character, link between consciousness and subconsciousness, the role of self-management in achieving the personal and group goals. 
The "Master KIT" technique synthesizes elements of suggestion, autogenic training and SMART-technologies, ideas from the method by Jose Silva (technique of controlling conscience, trans-surfing of the reality). The author of the "Master KIT" technique views the influence of unconscious components on the manifestation of personal features of clients. The key goal of the "Master KIT" technique is achieving the state of consciousness. Using the "Master KIT" technique by three thousand clients showed its efficiency in reaching material (financial) well-being, family happiness, and improving health; in total, up to $90 \%$ of the clients using the "Master KIT" technique experienced homeostasis and happiness .

Master KIT goes beyond the classical understanding of psychotherapy and allows us to consider the technique as a variant of self-regulatory practice with elements of psychotherapy. This technique is based on cognitive behavioral approach. While constricting the design of research it is permissible to consider the proximity of this methodology to the theoretical platform of cognitive psychology, activity psychology and cognitive-behavioral psychotherapy, and, therefore, formulate hypotheses and select research methods within this approach.

At present, the research is undergoing expertise by medical workers, to find out the correlation of psychotherapeutic effects with the effect of improving the feeling of health, activity and mood, in general, improving the life trajectory of a personality in positive direction.

\subsection{The Present Study}

The purpose of the study is to study the effectiveness of using Master-KIT technique in improving psychological characteristics of people as an example of an automated simulator for psychological self-regulation. Objective of the study is to conduct a theoretical review of methods for assessing the influence of similar methods, to conduct a physiological study of subjects, a psychodiagnostic examination of subjects with the help of battery tests and to carry out a sociological study of the social sphere.

\section{Method}

\subsection{Participants}

During the study, two groups of participants were recruited:

1. Participants who have already completed a long-term course (over one year) using technique

"Master KIT" (experienced users).

2. Participants who have not previously used the technique Master-KIT (beginners).

Criteria for recruiting the participants.

1. Age - 25-45 years old.

2. The absence of clinically pronounced mental disorders and a history of observation of psychiatrist

3. It is necessary to include men and women in the sample, the age range from 25 to 45 years, the level of education: secondaryprofessional and higher professional.

Table 1 presents the description of participants of the research carried out using Master-KIT technique.

Table 1. Characteristics of participants

\begin{tabular}{lllll}
\hline & $\begin{array}{l}\text { Number } \\
\text { participants }\end{array}$ & ofMan & Women & Medium age \\
\hline The newers & 55 & 16 & 39 & 33 \\
The newers repeteadly & 25 & 2 & 23 & 35 \\
Experienced users & 46 & 5 & 41 & 34 \\
\hline
\end{tabular}

\subsection{Measures}

"Methods of assessing the level of intuitiveness" by E. A. Naumenko (2001). The technique is designed to determine the levels of intuitiveness of the individuals. This test allows us to assess the severity of intuitiveness as a personality's feature. Received data for the scale:
a) intuitiveness
b) hypnoxity,
c) authenticity. 
The questionnaire consists of 45 statements, each of which is evaluated in three options: "yes, this is true", "no, this is not true", "true - something which is average". The intuitive scale includes 22 questions and statements.

Questionnaire "Lifestyle Index" by R. Plutchik, G. Kellerman and G. Conte ( Klubova, 1991). This test allows you to assess the degree of stress of psychological defense mechanisms. Received data for the scale:a) crowding out; b) regression; c) denial ; d) substitution; e) projection; f) compensation; g) overcompensation; h) rationalization; i) total stress. The questionnaire consists of 92 statements, with which the participant may agree or disagree.

\section{Scale of a depression by A. Beck (1976).}

This test allows to estimate the degree of depression symptoms. It is developed on the basis of the clinical observations which have allowed to reveal a limited set of the most relevant and significant symptoms of a depression and most often shown by patients of complaints. After correlation of this list of parameters with the clinical descriptions of a depression which are contained in the corresponding literature the questionnaire including 21 categories of symptoms and complaints has been developed. Each category consists of 4-5 statements which suit to specific displays / symptoms of a depression. These statements are ranged in process of increase in a specific contribution of a symptom to the general degree of a degree of depression. Each point has its meaning : 0 - the symptom is absent or minimal to 3 - the maximum of a symptom). Some categories include the alternative statements having equivalent specific meaning.

Scale of anxiety by Spilberger. It is the informative way of a self-assessment of level of anxiety at present (reactive anxiety as a state) and personal anxiety (as the steady characteristic of the person).

Processing of results includes the following stages:

1) Definition of indicators of situative and personal anxiety by means of a key.

2) Drawing up recommendations for correction of behavior of the examinee.

3) Calculation of medium indicator of the situational anxiety and personal anxiety and their comparative analysis in dependence, for example, on sex of examinees.

In the analysis of results of a self-assessment it must be kept in mind that the general total on each of subscales can be in range from 20 to 80 points. At the same time the it is higher than a total, the anxiety level is higher (situational or personal).

\section{Sociological questionnaires}

In order to obtain data sociological interviews were used. They helped to understand the motives that guided the respondent when deciding on the choice of methodology; his/het assessment of the results of interaction with the simulator in accordance with the objectives set, the degree of satisfaction with the technique, the study of social self-feeling; value orientations, changing of mind-sets.

\subsection{Procedure}

At the first stage of research 400 people who were interested in th technique MASTER KIT have been selected in order to participate in the research. The questionnaires, Spilrberger and Beck's questionnaires have been offered to them.

At the second stage the examinees who had admissible (standard indicators or those which were out of frame of standard) were sent to the clinical interview by psychiatrist. At this stage 101 examinees without the expressed mental disorders and which don't have a history of observations by psychiatrist have been selected.

At the third stage all the beginners have been offered free access to a technique of "Master KIT". From them 25 people began to use actively a technique of "Master KIT" (not less than 5 times a week). In 3 months from the moment of their first use of a technique it was offered to them to pass again neurophysiological and psychodiagnostic inspection and also a questionnaire in order to register the changes ( the same methods were used). In 3 months from the beginning of a research the third research group has been created.

\section{Results}

Table 2 presents Wilcoxon criteria was applied to check the orientation of changes among "beginners" (control group). The period between researches was 3 months. The amount of selection didn't exceed admissible 50 people. 
Table 2. Wilcoxon criteria

\begin{tabular}{llccll}
\hline Wilcoxon & \multicolumn{1}{l}{ Valid } & $\mathrm{T}$ & $\mathrm{Z}$ & $\mathrm{p}$-value \\
\hline Clinical questionnaire & $\begin{array}{l}\text { Sum on the scale } \\
\text { typeof response }\end{array}$ & & 77,0000 & 2,085714 & 0,037005 \\
Beck & Beck & 23 & 57,5000 & 2,448404 & 0,014350 \\
Scale of anxiety & Group 1 & 22 & 50,0000 & 2,483622 & 0,013006
\end{tabular}

Scale of a depression by A. Beck.

Orientation of changes in groups of beginners and repeated beginners is a median: 6,0000 and 3,5000 respectively). This data speak about decrease in indicators of a depression.

$\mathrm{T}$ empirical $=57,500 ; \mathrm{p}=0,01434$.

$\mathrm{T}$ critical for selection 23 persons $=83$.

Therefore, $\mathrm{P}_{\mathrm{emp}} \cdot \mathrm{P}_{\mathrm{kr}^{-}}-$the differences are statistically significant

Situational anxiety (Scale of anxiety by Spilberger).

Orientation of changes in groups of beginners and repeated beginners shows the reduction of an indicator on a scale (mediana:43,0000 and 40,0000 respectively).

Data speak about decrease in indicators of anxiety within a moderate anxiety (range of 31-44 points).

$\mathrm{T}$ empirical $=50,000 ; \mathrm{p}=0,01300$.

$\mathrm{T}$ critical for selection of 22 persons $=75$.

Therefore, $\mathrm{P}_{\mathrm{emp}} \cdot \mathrm{P}_{\mathrm{kr}}$ - the differences are statistically significant

The Table 3 shows the factor analysis with the following results

Table 3. Factor analysis in the group of beginners

\begin{tabular}{lc}
\hline Beginners Principal components (Marked loadings are $>, 400000$ )Factor 1 Factor 2 \\
\hline the sum on an anxiety scale & $\mathbf{- 0 , 9 5 5 9 9 0 , 2 1 6 9 5 1}$ \\
the sum on a scale of a neurotic depression & $\mathbf{- 0 , 9 3 5 1 3 0 , 2 6 3 0 0 9}$ \\
the sum on a scale of vegetative violations & $\mathbf{- 0 , 9 1 9 4 5 0 , 2 8 3 4 1 6}$ \\
Beck & $\mathbf{- 0 , 9 3 1 2 9 - 0 , 0 6 6 4 0 5}$ \\
Situational anxiety & $\mathbf{- 0 , 7 3 6 3 2}-0,270498$ \\
Personal anxiety & $\mathbf{- 0 , 7 5 1 5 1 - 0 , 3 6 9 8 1 6}$ \\
Intuitive ability & $\mathbf{- 0 , 9 0 3 0 6} 0,178215$ \\
Use of an intuition & $\mathbf{- 0 , 8 4 0 4 7 0 , 1 3 6 4 2 1}$ \\
Obligation of concerning & $\mathbf{- 0 , 9 6 1 2 1 0 , 1 8 2 8 4 2}$ \\
Obligation of concerning about others & $\mathbf{- 0 , 9 5 7 7 9 0 , 2 1 0 8 5 9}$ \\
Self-assessment and rationality of thinking & $\mathbf{- 0 , 9 4 3 2 7 0 , 2 5 1 7 4 6}$ \\
Intuitivism & $\mathbf{- 0 , 8 7 3 0 0 0}, 086016$ \\
Anxiety & $\mathbf{- 0 , 9 5 0 2 4 - 0 , 0 6 4 5 6 6}$ \\
\hline
\end{tabular}


Table 4 shows the factor analysis in the group of experienced users

Table 4. Factor analysis in the group of experienced users

\begin{tabular}{lll}
\hline Experienced & Factor 1 & Factor 2 \\
\hline he sum on an anxiety scale & $\mathbf{0 , 6 9 5 2 9}$ & 0,184489 \\
the sum on a scale of a neurotic depression & $\mathbf{0 , 7 0 1 0 3}$ & $-0,086150$ \\
the sum on a scale of vegetative violations & $\mathbf{0 , 6 8 0 8 0}$ & $-0,007533$ \\
Beck & $-0,24509$ & $-0,058980$ \\
Situational anxiety & $\mathbf{- 0 , 6 0 0 9 7}$ & 0,272446 \\
Personal anxiety & $\mathbf{- 0 , 6 8 8 2 3}$ & 0,275494 \\
Intuitive ability & 0,16656 & $\mathbf{- 0 , 6 4 0 2 0 4}$ \\
Use of an intuition & 0,04344 & $\mathbf{- 0 , 4 7 8 7 5 0}$ \\
Obligation of concerning & $\mathbf{0 , 4 6 6 6 1}$ & $-0,145838$ \\
Obligation of concerning about others & $\mathbf{0 , 5 3 4 7 5}$ & $-0,301001$ \\
Self-assessment and rationality of thinking & $\mathbf{0 , 6 0 7 7 4}$ & $\mathbf{- 0 , 4 4 0 3 8 2}$ \\
Intuitivism & $-0,01571$ & $\mathbf{- 0 , 4 8 6 8 4 1}$ \\
Anxiety & $\mathbf{- 0 , 4 5 9 9 2}$ & $-0,020753$ \\
\hline
\end{tabular}

These data show a positive effect on the emotional state of users when using methods in the short-term period. Reducing the level of neuroticism indicates a less pronounced stress after the start of using the technique. This relates also to for depressive anxiety symptomatology.

Table 5 shows the results of sociological questionnaire which was carried out among all the participants.

Table 5. The changes in the life of participants after using Master-KIT technique, \% (the respondents could use all the appropriate answers)

\begin{tabular}{ll}
\hline Types of changes & Result \\
\hline The personal life has become better & 20,9 \\
My health and the health of my children and relatives has become better & 17,6 \\
The material state has been improved & 27,5 \\
I could find my vocation, favourite activity & 14,3 \\
Another & 6,6 \\
It's difficult to answer & 13,2
\end{tabular}

Table 6. New life possibilities that the participants could get after using «Master KIT», \% (the respondents could use all the appropriate answers)

\begin{tabular}{ll}
\hline Answers & Result \\
\hline to find and remove the blocks, mind-sets, that were the barriers in my life & 36 \\
to correctly set the goals and find the direct ways to them & 18,9 \\
to perceive everything that happens in this life through the prism of positive. & 31,5 \\
To learn self-discipline & 8,1 \\
Another & 0,9 \\
It's difficult to answer & 4,5 \\
\hline
\end{tabular}

Table 5 and Table 6 show the new possibilities which the participants could get after using Master-KIT. The participants also could answer how did the technique exactly help them. Due to the results we can say that the participants could find and remove the blocks, mind-sets, that were the barriers in their life, became more positive, more organized and self-discipline. There were also positive changes in the relationships. The 
participants tell about the improving the relationships with relatives, friends, or finishing the relationships which caused the anxiety and negative emotions.

\section{Discussion}

The main results can be summarized as follows. The feature of a technique of "Master KIT" is that the direct interaction between the person and therapist doesn't exist. Therefore this technique can be called as a self regulated practice with the elements of psychotherapy. The main technique for psychological research is questionnaire method with the proved psychodiagnostic validity. Also the sociological and neurophysiological methods can be applied. In the scale of emotional disorders the negative impact on the emotional sphere of the users was not revealed while using the Master-KIT in short-term period( 3 months)

The nature of connection between scales differs at all three-groups. At the same time the average indicator and the median in the scale of neurotization is less among the experienced users than among the beginners. We observed narrowness of connections of a large number of scales among the beginners, but during the repeated measurement and also at experienced users, these connections are observed at narrow group of scales. Possibly, use of a technique leads to a certain unification of mechanisms of psychological regulation while solving psychological tasks, including adaptation to a stress. When using a technique there is a change in psychological features of users which can be recorded in the short-term period. It is possible that such differences will be observed as well in more long-term perid. In the short-term period positive influence on emotional state of users is noted.

So, the smallest expressiveness is observed at experienced users, and the greatest - at repeated group. Perhaps, it is connected with rather bigger importance of intuitive forecasts for experienced users while in the short-term period there is an increase in assessment of own predictive abilities. On a scale of obligation the tendency to increase of requirements to itself and people around is traced. The smallest expressiveness is observed among the beginners, and the highest - in the long-term period.

A positive attitude, the correct setting of goals and the ability to find and remove the mind-sets and and blocks are new skills in the life of the respondents. After completing the course of study, the respondents felt changes in one or another area of life. Some have improved relationships, someone was able to find their purpose, someone managed to improve their financial situation, some solved some problems with health. Someone just felt a change at the level of emotions, but so far they can not give them a verbal formulation. Any technique, proposed by the scholars belonging to psychological and psychotherapeutic schools, is a system.

The "Master KIT" technique, test, proved its efficiency and viability as practice-oriented authors' system. Our further research will be aimed at measuring the correlation of the technique with medical indicators of improving the feeling of health, activity and mood, and at finding out the possibility to form the social intellect of a personality with this technique, which is demanded to preserve homeostasis in the society.

\subsection{Limitations of the Present Study}

This research helped us to fix the dynamics of psychological state of the participants after using Mster-KIT technique. But the most correct results can be gotten while carrying out additional researches using

Longitudinal method with the period of study not less than one year. During the research the critical negative influence on the emotionaland personal sphere of participants was not defined. But the data received in the research are not enough in order to get exact answer about the psychological security of the technique. The special longitudinal research and studying the spread of mental and emotional disorders among the participants is required. But this type of research requires a special ethic expertise. The question of the mechanisms of psychological impact on users of technique also remains open. The current conclusion, coming from the research, argues in favor of the formation of features of the interaction of intuitive and analytical components of psychological self-regulation. However, a more accurate answer can be obtained by a detailed study of the users' personality. In addition, this study does not address the issue of the psychological description of the processes occurring with users while working with the technique. The weakest point in this study is gender correlation. If the age group is fairly balanced, the number of men in all groups is significantly lower than women. The study of differences by gender did not reveal a significant difference, however, for a more relevant extrapolation of the obtained data to the general population, an additional number of male subjects is required. On the other hand, subsequent studies will shed light on the question of the degree of gender difference. 


\section{References}

Adler, A. (1986). Individual psychology. History of foreign psychology. 1930s-1960s (texts), Moscow.

Adler, A. (2011). The science of living. Martino Fine Books, Eastford, 266.

Adler, A. (2010). Understanding Human Nature. Martino Fine Books, 302.

Adler, A. (2009). Understanding life: an introduction to the psychology of A. Adler. Oneworld Publications, 200.

Ahtinen, A., Mattila, E., Valkkynen, P., Kaipainen, P.,Vanhala, T., Ermes, M., Lappalainen, R. (2013). Mobile Mental Welness Training for Stress Management:Feasibility and Design Implications based on a One-Month Field Study. JMiR mHealth and uHealth, 1(2). https://doi.org/10.2196/mhealth.2596

Anokhin, P.K. (1998). Selected works: Cybernetics of functional systems. Ed. K.V. Sudakov. Moscow. 400.

Ahtinen, A. (2013). Mobile Mental Wellness Training for Stress Management: Feasibility and Design Implications Based on a One-Month Field Study. JMIR mhealth whealth, 1(2), 11. https://doi.org/10.2196/mhealth.2596

Arean, P. (2016). The Use and Effectiveness of Mobile Apps for Depression: Results from a National, Fully Remote Clinical Trial. J. Med. internet Res., 18, 1-13. https://doi.org/10.2196/jmir.6482

Batthuany, A. (2016). Logotherapy and Existential Analysis: Proceedings of the Viktor Frankl Institute Vienna L, Springer, 1, 469. https://doi.org/10.1007/978-3-319-29424-7

Beck, A. (1976). Cognitive therapy and emotional disorders. NewYork: Intern.Univ.press, 356.

Bennike, I., Wieghorst, A. \& Kirk, U. (2017). Online -based Mindfulness Training Reduces Behavioral Marks of Mind Wandering. J.Cogn Enhanc. https://doi.org/10.1007/s41465-017-0020-9

Cohn, M. (2009) .Happiness unpacked :positive emotions increase life satisfaction by building resilience. Emotion, 9(3), 361-8. https://doi.org/10.1037/a0015952

Christopher, M.S.,Charoensuk,S.,Gilbert,B.D.,Neary,T.J., \& Pearce,K.L. (2009). Mindfulness in thailand and the united states: A case of apples versus oranges? Journal of Clinical Psychology, 65(6), 590-612. https://doi.org/10.1002/jclp.20580

Creswell, J. (2017). Mindfulness Interventions. Annu. Rev. Psychol., 68(1), 491-516. https://doi.org/10.1146/annurev-psych-042716-051139

Cuijpers, P. (2012). The efficacy of non-directive supportive therapy for adult depression:Ameta- analysis. Clin. Psychol. Rev., 32(4), 280-291. https://doi.org/10.1016/j.cpr.2012.01.003

Dispenza, J. (2008). Evolve Your Brain: The Science of Changing Your Mind, HCI. Reprint edition, 528.

Dispenza, J. (2013). Breaking the Habit of Being Yourself: How to Lose Your Mind and Create a New One, Hay House, 360 .

Dispenza, J. (2015). You are the placebo: making your mind better. Hay House, 416.

Dispenza, J. (2014). You are the placebo: meditation 1: changing 2 beliefs and perception. Hay House, 200.

Frankl, V. (2006). Man's search for meaning. Beacon Press, 184.

Frankl, V. (2014). The will of meaning: foundations and applications of logotherapy. Plume, 176.

Frankl, V. (1986). From psychotherapy to logotherapy, revised and expended. Vintage, 318.

Freud, S. (1989). Psychology of the unconscious. Moscow.

Freud, S. (2006). The main psychological theories in psychoanalysis. Moscow, 400.

Fromm, E. (1997). To have or to be. Translation from English, Minsk, Edited by Ilin V.P., 206-411.

Fromm, E. (2013). The revision of psychoanalysis. Open Road Media, 137.

Fromm, E. (2006). The art of being. Blackstone Audio Inc, 126.

James, U. (1991). Psychology. Moscow.

Jung, C. (1994). Psychology of the unconscious. Moscow.

Kehoe, J. (2006). Mind Power into the 21st Century: Techniques to Harness the Astounding Powers of Thought. Zoetic Books, 181.

Kehoe, J. (2001). The practice of happiness. Zoetic Books, 128. 
Köhler, W. (1998). Main directions of psychology in the classical works. The mentality of apes. Koffka K. Bases of mental development. AST-LTD, 704.

Kutter, P., Muller, T. (2011). Psychoanalysis. Introduction to the psychology of unconscious processes. Moscow, Kogito-centre, 384.

Maslow, A. (1995). Motivation and personality, Course in practical psychology, ed. R.R. Kashapov. Izhevsk.

Naumenko, E. (2001). Intuitiveness as personal quality. Dissertation, Saint-Petersburg.

Psychologist told how to reach the happiness. Retrieved from http://psychlib.ru/mgppu/periodica/Pedologia071931http://sci-dig.ru/statyi/kak-dostich-schastya-rasskazalipsihologi

Raigorodskiy, D.Y. (1996). Theories of personality in the West European and American psychology. Samara, Bakhrakh, 480.

Sochivko, D.V., Polyanin, N.A. (2009). Youth of Russia: educational systems, subcultures, correctional institutions. Moscow.

Uznadze, D.N. (1949). Experimental bases of mindsets theory. Tbilisi.

Uznadze, D.N. (1961). Bases of mindsets theory. Tbilisi.

Wright, J., Wright, A., Albano, A., Basco, M., Goldsmith, L., Raffield, T., Otto, M. (2005). Computer-assisted cognitive therapy for depression:maintaining efficacy while reducing therapist time. American Journal of Psychiatry, 1(162). https://doi.org/10.1176/appi.ajp.162.6.1158

Zarakovskiy, G.M. (2009). Quality of life of the Russian citizens: psychological aspects. Smysl, Moscow, 320.

\section{Copyrights}

Copyright for this article is retained by the author(s), with first publication rights granted to the journal.

This is an open-access article distributed under the terms and conditions of the Creative Commons Attribution license (http://creativecommons.org/licenses/by/4.0/). 